\title{
Relación de mercancías musicales de Otavalo y El Alto con la industria cultural de Ecuador y Bolivia ${ }^{1}$
}

\section{Raúl Moncada Landeta}

Recibido: 3 de octubre de 2014

Aceptado: 6 de noviembre de 2014

\section{Resumen}

Este artículo analiza la producción de mercancías musicales: cds y dvs, en Otavalo y El Alto, relacionada con la industria cultural y mediática de Ecuador y Bolivia. A partir de una breve contextualización histórica y cultural de la música en estas dos ciudades, se caracteriza instrumentos musicales, ritmos y usos de la música en rituales y por parte de ensambles. Hay reflexión sobre investigaciones de la industria cultural musical que dan cuenta de las mutaciones que en las últimas décadas han vivido empresas, artistas y tendencias musicales relacionados con comunidades indígenas andinas. Las fuentes del estudio son entrevistas a informantes claves, análisis de documentos históricos, publicaciones de medios impresos, archivo audiovisual y digital, así como documentos de internet.

\section{Pallabras clave}

Producción, mercancías musicales, industria cultural, música popular, Otavalo, El Alto

\section{Relation of musical goods of Otavalo and El Alto with the culture industry of Ecuador and Bolivia}

\section{Abstract}

This article analyzes the production of musical goods: cds and dvs, in Otavalo and El Alto related to the cultural industry and mediatica of Ecuador and Bolivia. From a brief historical and cultural contextualization of the music in these two cities, there are characterized musical instruments, rhythms and uses of the music in rituals and on the part of ensambles. There is reflection on the musical cultural industry research that account for the mutations that companies, artists and musical trends related to Andean indigenous communities have lived in recent decades. The study sources are interviews with key informant, analysis of historical documents, publications of printed media, audiovisual and digital file, internet documents.

http://dx.doi.org/10.5209/rev CDMU.2014.v25.47474

Otavalo, El Alto

1

Este artículo es parte de un capítulo de la Tesis del Autor, en fase de redacción, para la obtención del Título de Doctor en Ciencias Sociales con especialización en Estudios Andinos. 


\section{INTRODUCCIÓN}

En este trabajo se presenta un análisis sobre estudios de industria cultural musical relacionados con la producción musical en Otavalo y en El Alto. Se explica la cuestión: ¿cuál es la relación entre la producción de mercancías musicales en Otavalo y en El Alto con la industria cultural musical de Ecuador y de Bolivia?

Es un trabajo de carácter cualitativo, la metodología aplicada se sustentó en preguntas de investigación que guiaron el proceso de delimitación de los objetos de estudio, la orientación del estado del arte, la aproximación teórica y la definición de técnicas que facilitaron la recolección de la información. No es un estudio comparado, es un examen de dos casos en contextos propios y originales que tienen algunas características comunes pero que no se consideran deterministas o causales entre las dos ciudades de los dos países. Cada caso (comunidad quichwa en Ecuador y aymara en Bolivia) tiene sus propias características culturales, económicas, políticas y sociales.

Una de las técnicas utilizadas fue la entrevista en profundidad a informantes claves: se dialogó con especialistas, productores, comerciantes, músicos, danzantes, estudiosos seleccionados por su nivel de comprensión o dominio cognoscitivo acerca de la relación producción/consumo de mercancías musicales e industrias culturales en Otavalo y en El Alto.

Otra técnica que se aplicó fue el análisis de información documental digital o impresa para indagar en fuentes bibliográficas, hemerográficas y audiovisuales; documentos y textos que se encontraron en bibliotecas, centros de documentación, archivos públicos, sitios de venta de cds y dvds en Otavalo, Quito (Ecuador), El Alto y la Paz (Bolivia), archivos individuales o privados del Autor y de personas que generosamente colaboraron con textos para compendiar información secundaria o indirecta; con esta técnica se redactó un estado del arte sobre artículos publicados en el lapso 2005-2013 en revistas indexadas en América Latina que tienen versión digital en línea.

Este artículo destaca la rica significación que demuestran estas comunidades indígenas a partir de sus ejes musical, ritual, social y simbólico relacionados con las mercancías y las industrias culturales musicales, enfrentadas a otros sectores sociales que, en cambio, se consolidaron desde los procesos que occidente demanda para la realización de la ganancia o rentabilidad, incluso confrontadas con procesos de exclusión, marginación y humillación que sectores dominantes han impuesto en cada país.

Se parte del contexto cultural e histórico de Otavalo y El Alto. Se analiza el proceso mestizo propio y notable que se desarrolló en América Latina; la música, sus instrumentos, ritmos, melodías y usos de estos pueblos indígenas se han producido gracias al proceso de sincretismo en el que la presencia europea hebreo cristiana católica se conjugó con las cosmovisiones de los pueblos originarios. En Otavalo y El Alto sus comunidades han logrado una integración intercultural urbana en el contexto de los últimos sesenta años que han vivido sus países. Al final se caracteriza la producción de música de Otavalo y El Alto en su relación con la industria cultural y mediática de Ecuador y Bolivia. 


\section{CARACTERÍSTICAS DE LA MÚSICA DE OTAVALO Y EL ALTO EN SUS CONTEXTOS: 1960-2000}

La música popular de Otavalo y El Alto se sitúan en un contexto histórico, económico, geográfico, cultural, social y político, sus músicas se condicionan por los aspectos étnicos, organizativos, territoriales, tradicionales, identitarios. Tal como reflexiona Hormigos (2010, p. 95), los productores y comerciantes de mercancías musicales en Otavalo y en El Alto están inmersos en prácticas sociales vinculadas a la música, estas comunidades dan sentido a sus canciones o melodías, ritmos e instrumentos desde sus cosmovisiones y contexto cultural: lengua, universo simbólico, costumbres, creencias, rituales, ceremonias; a partir de todo lo cual la música también adquiere un papel comunicativo.

El proceso de mestizaje de la multiplicidad de culturas y su interacción entre indígenas, mestizas y afrodescendientes con otras culturas en el mundo se expresa en diversos campos, entre ellos la música y los rituales de estas comunidades. El sincretismo ha sobrevivido en fiestas, producción artística, costumbres, modos de relacionarse en el mundo comunitario y familiar de estas comunidades de Latinoamérica dentro de una diversidad cultural.

Un ejemplo de esta fusión cultural e histórica la tiene la guitarra como instrumento musical que ha condicionado la emergencia de determinados ritmos o aires de la música popular (Godoy, 2005, p. 170). También los instrumentos de comunidades andinas han sido utilizados por mestizos.

Varios de los instrumentos musicales indígenas andinos provienen de los pueblos kichwas de los Andes. Estos instrumentos, desde la época colonial, los asumieron los mestizos, como en el caso del rondador ${ }^{1}$. (Rodríguez y Tierra Libre, 2012)

Respecto de Ecuador y Bolivia, el instrumento común de ensambles indígenas y mestizas de música popular andina, que deviene históricamente de épocas prehispánicas, encontradas en cerámica y hueso en Ecuador y Bolivia, es la quena ${ }^{2}$, (Mullo, 2009, p. 46), eje de las melodías de varias agrupaciones de música popular en Otavalo y El Alto que lo usan como referente simbólico.

La música popular se relaciona con las cosmovisiones de poblaciones indígenas que se socializa por mecanismos culturales de generación en generación; las comunidades de Otavalo en Ecuador y de la ciudad de El Alto en Bolivia han desarrollado ritmos y melodías sobre la base de sus referencias, identidades y símbolos culturales. Esta concepción lo comparte Godoy $(2005$, pp. 165, 167) cuando afirma que la música en Ecuador es el resultado de la integración con otros ritmos y otras cosmovisiones populares.

1 El rondador pertenece a la familia de flauta de pan conformado por un conjunto de tubos de carrizo en el número de entre 20 y 22, su interpretación es por el soplo de pares de tubos, que le da la sensación de dúo en la ejecución de melodías (Rodríguez, 2008, pp. 32, 33).

2 La quena es un instrumento de viento milenario, data de antes de la llegada de los españoles, es uno de los instrumentos más difundidos a nivel latinoamericano y mundial. Es una flauta vertical con una embocadura similar a una "u", con seis orificios en la parte posterior y uno en la anterior. De gran variedad de tamaños y tesituras, construidas fundamentalmente de caña (Cavour, 2010, pp. 63 y ss.). 
Existen ensambles originales de música popular andina en comunidades indígenas como Otavalo en Ecuador y El Alto en Bolivia, que interpretan instrumentos de viento como quena, zampoña o siku ${ }^{1}$, $\operatorname{tarka}^{2}$, flautas andinas, rondador, pingullo ${ }^{3}$, pífano, paya; varios ensambles suelen fusionarlos con cordófonos tales como violín, guitarra, bajo eléctrico, charango, bandolín ecuatoriano; y con percusión, especialmente con el bombo.

A partir de 1990 los músicos urbanos ampliaron sus instrumentos de cuerda como charango y guitarras que los volvieron electroacústicos para interpretarlos con micrófonos y amplificadores y combinarlos con otros instrumentos como teclado, bajo eléctrico, batería electrónica (Cavour, 2010, p. 421).

\section{EL CONTEXTO ACTUAL DE OTAVALO}

Otavalo es un cantón de la provincia de Imbabura, situada a 110 kilómetros al norte de Quito, a 20 kilómetros al sur de Ibarra (Capital de la Provincia de Imbabura), a una altura de 2.565 metros sobre el nivel del mar. El cantón Otavalo tiene una superficie de 579 kilómetros cuadrados (Gobierno Autónomo Descentralizado de Otavalo, 2013, p. 9).

De acuerdo con el Censo de Población y vivienda realizado en el 2010 por el Instituto Nacional de Estadística y Censo, INEC, la población de Otavalo es de de 104.874 habitantes. El 37.52\% vive en el área urbana y el $62.48 \%$, en las parroquias rurales. Otavalo es mayoritariamente indígena, con el $57,2 \%$ de origen kichwa ${ }^{4}$ (Gobierno Autónomo Descentralizado de Otavalo, 2013, pp. 13, 289, 290).

Entre las décadas de los 70 y 90 del siglo XX en Otavalo se activaron grupos culturales de comunidades Kichwas en Peguche, Quinchuqui y otros sectores aledaños para reivindicar derechos culturales, conocimientos, valores, dinamización y uso del idioma kichwa (Kowii, 2005, p. 2).

Desde los 90 del siglo pasado, en Otavalo emerge un movimiento político y cultural

1 La zampoña es un instrumento de las flautas de pan compuesto por varias cañas de tubos cerrados de distinta longitud, en aymara se lo conoce con el nombre de siku (Rodríguez, 2008, p. 15). El siku, tradicionalmente se lo ha interpretado en rituales de época seca. Se lo ejecuta en pares de instrumentos, dos hileras de tubos que conforman mitades, la una mitad denominada siku ira y la segunda, siku arka. Construido de tuquru o cañahueca de carrizo, es heptáfono y tiene trece tubos. (Ordoñez, 2011, p. 326).

2 La tarka o anata es un aerófono que pertenece a la familia de los pinquillos, posee una embocadura de pico y canal de insuflación, elaborado de modo compacto en un solo madero macizo. Con seis orificios en el lado frontal y un orificio en la base. Es un instrumento que aparece decorado en su tallado, su sonido es grave y profundo (Cavour, 2010, pp. 124-131). Hay dos tipos de tarkas: "las blancas, de madera tarco, un poco redondas y maciza, fabricadas en Pampa Aullugas, en la ciudad de Oruro y en el sur de la Paz, y luego las cuadradas, más delgadas de color café rojizo, de madera mara, fabricadas en Jach'a Walata (Omasuyos, La Paz) y por residentes walateños en la ciudad de El Alto..." (Gérard, 2010, p. 72)

El pingullo, de uso preferencialmente indígena, es una flauta vertical con embocadura de pito con tres orificios que se digitan con la mano izquierda, fundamentalmente fabricado de tunda, zuro y carrizo. El ejecutante se acompaña con un pequeño tambor (Rodríguez, 2008, pp. 40, 41).

$4 \quad$ Las comunidades indígenas Kichwas conforman la nacionalidad poblacionalmente más importante en el Ecuador, se sitúan en la mayoría de provincias de la Sierra y parte de la Costa y la Amazonía. Los kichwas han vivido sincretismo del cristianismo que trajeron los españoles y de sus referencias culturales que remiten a códigos lingüísticos, interculturalidad entre seres humanos y principios de relación con distintos ámbitos como el cosmos y el resto de culturas del Ecuador (Kowii, 2005, p. 3). 
...sustentado en un entramado de comunas, con redes familiares que atravesaban el mercado, la vida urbana y los espacios públicos locales, y con una presencia étnica y política con proyección local y nacional (Ortiz, 2012, p. 185).

Las relaciones interculturales de indígenas y mestizos sobre la base de esfuerzos de integración étnico-social fue impulsado por el Municipio desde el año 2000, cuando se eligió al primer Alcalde indígena, Mario Conejo; esta propuesta de integración le valió a este cantón la declaración de capital intercultural de Ecuador por el Congreso de la República, en octubre de 2003 (Lalander, 2009, p. 108).

En Otavalo la música popular que cultivan y escuchan estas comunidades indígenas es considerada un valor de uso simbólico que hay que preservarla; la construcción y comercialización de instrumentos con que se ejecuta esta música se orienta al consumo de músicos de ensambles o de grupos de la sierra norte que participan en fiestas, celebraciones y rituales; además de turistas y público local. La fabricación de estos instrumentos se realiza de modo artesanal a partir de organizaciones familiares, por ejemplo, padre, esposa e hijos participan del proceso de producción de instrumentos andinos (Cachiguango, entrevista, 2012).

\section{EL CONTEXTO ACTUAL DE EL ALTO}

La ciudad de El Alto está ubicada en la meseta altiplánica al oeste de la Paz y como parte de su área metropolitana, situado entre 4.150 y 4.010 metros sobre el nivel del mar, al occidente de Bolivia, Provincia Murillo (Gobierno Autónomo Municipal El Alto, 2014). Tiene una superficie de 1.042 kilómetros cuadrados, considerada la ciudad más alta del mundo (Ecured, 2014).

Escobar (2010, p. 54) asegura que en El Alto, una ciudad que se forjó en los últimos treinta años, existe una escuela de otra manera de pensar desde la óptica comunal y cultural. En el Alto, con casi un millón de habitantes, se vive una versión joven, sincrética y dinámica de la cultura aymara urbana. Los jóvenes se insertan social y culturalmente en barrios, establecimientos educativos y en los grupos y fraternidades. Una sección especial en las entradas de El Alto lo conforman los jóvenes que organizan coreografías basadas en ritmos de tinku o de caporales, incluyen la música techno o el rap a los arreglos musicales aymaras (Albó, citado por Tassi, 2010, p. 26).

Según De Munter (2010, p. 250), un estudio aplicado en El Alto señala que la mayoría de sus habitantes han logrado un claro nivel de mestizaje económico o complementación económica, combinando una participación en el mercado de las grandes ciudades y una interacción en base a lazos de reciprocidad con el mundo de las comunidades originarias. Otra investigación sostiene que los productores o comerciantes del sector informal de El Alto tienen un comportamiento heterogéneo, se inscriben en un contexto mesoeconómico y son permeados por su cultura (Parra, 2009, p. 1). 
En El Alto, la producción musical chicha ${ }^{1}$ se sustenta en relatos sentimentales y de padecimiento frente a la adversidad y la subsistencia que los migrantes de origen campesino advierten. Otro ámbito musical y sus valores de uso simbólico están ligados a rituales en los que se interpretan ya sea con instrumentos autóctonos, como zampañas, sikus, tarkas, quenas, mohoceños ${ }^{2}$, que se presentan en fiestas como los carnavales; o instrumentos de bronce: característicos de bandas integrada por alrededor de cien músicos, que interpretan, por ejemplo, el ritmo de ch'uta (Mamani Colque, entrevista, 2012).

\section{INDUSTRIA CULTURAL, GLOBALIZACIÓN Y NEOLIBERALISIMO}

Los estudios sobre la industria cultural musical en América Latina fueron incipientes durante 25 años, desde mediados de 1970 hasta fines de la década de 1990, investigaciones cuyas temáticas fundamentales se inscribieron en: "sociedad y cultura de masas", "aldea global", "imperialismo cultural" (Torrico, 1999, p. 2). Este panorama de escasos estudios aplicados en América Latina es la tónica que se ha mantenido en los últimos años, mediados de la década de 2000 hasta el $2013^{3}$, aunque estos recientes estudios han ampliado las temáticas anteriores a nuevos problemas de investigación relacionados con la "globalización y la sociedad digital".

El neoliberalismo facilitó la mundialización y concentración de los intercambios de bienes simbólicos producidos por países del centro, especialmente de Estados Unidos y Europa, en desmedro de la producción cultural de países latinoamericanos cuya tendencia fue la de importadores de bienes culturales y la escasa capacidad de exportación de productos culturales propios, entre ellos los musicales. La pérdida o ausencia de decisión y control estatal y la creciente privatización transnacional perjudicó a las industrias culturales de los países de la región. Con el neoliberalismo, las culturas y los productos del trabajo artístico en los países latinoamericanos fueron relegados, debilitados en las últimas décadas.

El neoliberalismo se implantó a nivel global para dos propósitos fundamentales: el primero, posicionar sentidos eficaces al proyecto de globalización y acumulación del capital de élites pertenecientes a los países del centro.

...En la actualidad los movimientos mundiales de la industria musical alcanzan los 40 mil millones de dólares, 90 por ciento de los cuales se concentran en las seis mejores: BMG, EMI, SONY, Warner, Polygram y Universal (Yúdice citado por García Canclini, 2000, p. 93)

Y el segundo propósito fue promover la producción de mercancías, entre las que se encuentran las musicales: cds y dvds, para la rentabilidad: productos musicales simples, cortos, divertidos, superabundantes y volátiles. Estas mercancías producen rentabilidad por la simpleza, elementalidad o sencillez de las canciones; es una producción similar a la información de los medios masivos que critica Ramonet (2002), no hay complejidad de los temas, igual que la información, las canciones priorizan y se promocionan gracias a la imagen de los

$1 \quad$ La música chicha es una mezcla entre el ritmo de la cumbia colombiana con ritmos bolivianos como el huayño, la morenada, entre otros, su orquestación se crea de un trabajo electrónico en un estudio de grabación.

2 Mohoceños, se clasifican en flautas traversas y verticales de diversos tamaños fabricado de cañahueca, se lo interpreta en conjunto denominado tropa que integra a mohoceños con las diversas tesituras de más de dos octavas y de estructura pentatónica (Cavour, 2010, pp. 133-138).

3 Se revisaron revistas indexadas especializadas en comunicación publicadas en el período 2005-2013. 
videoclips. Además, los vídeos y audios de canciones generan diversión, espectáculo que se expresa en lo dramático, en el sufrimiento, en lo patético, como el principal género utilizado en los textos musicales.

A nivel global prevalecen las empresas transnacionales que contienen a grandes medios masivos y al internet con los que dominan a distintos fragmentos de la industria cultural.

Los medios pertenecen a grupos mediáticos (Murdoch, Google, Blackberry) que se expanden con la revolución digital, que rompen las barreras, con la espectacular expansión de internet. Se mezclan todas las esferas: la cultura de masas, la información, la comunicación y el internet. Los grupos mediáticos que manejan todas estas esferas son multinacionales, planetarios. (Ramonet, 2010)

Según Harvey (2003, p. 80), la prensa económica logró hacer creer que la globalización es algo nuevo, como un ardid publicitario, cuando ha sido un proceso relacionado con el aprovechamiento de un ajuste financiero internacional. Este autor demuestra que la globalización no es nueva, hay expansión espacial de Estados Unidos y Europa para el dominio, igual que en el siglo XVI lo hicieron España, Inglaterra y Alemania.

Con el modelo neoliberal, la producción, distribución, comercialización, consumo e intercambio de bienes simbólicos se realizan en un entramado de procesos. Al mismo tiempo que subsisten redes de intercambio simbólico provenientes de países del centro, escasa industrias culturales de los países de la periferia, piratería que privilegiaron características occidentales de mediación tecnológica o instrumental de comunicación y de rentabilidad.

...Ha surgido un vasto territorio empresarial en torno a la invención y la innovación que suministra por doquier nuevas tecnologías de consumo, producción, circulación, gobernanza, poder militar, vigilancias y administración... La cultura capitalista se obsesionó por el poder de la innovación tecnológica convertida en objeto fetiche de deseo para el capitalista. (Harvey, 2014, p. 104)

Este proceso mundial se contrasta con las mediaciones de saber no occidental de culturas populares que crean procesos de producción simbólica relacionados con identidades y otras referencias culturales de interacción comunitaria. En países como Ecuador y Bolivia, frente a la exigua industria cultural musical de carácter endógeno dedicada a los artistas nacionales, surgieron pequeños y dispersos negocios de carácter informal, de producción musical artesanal local, actividad denominada "piratería", que mermó ingresos de grandes industrias y afectó la recaudación de impuestos por parte del Estado (Torrico y Baldivia, 2005, p. 78). La piratería también prosperó gracias al acceso a nuevas tecnologías que facilitaron la reproducción de productos culturales, como por ejemplo los musicales, a mucho menor costo que las grandes empresas de producción masiva. Estas innovaciones en el campo de la industria cultural musical beneficiaron a sus empresas productoras de estas tecnologías en desmedro de las industrias musicales del disco acetato; es una contradicción del capital, porque crea rentabilidad para unas empresas generadoras de tecnología pero afecta a empresas con aparentemente anticuados equipos que monopolizaban con sus estudios las grabaciones de artistas.

Los cambios tecnológicos en el capitalismo, a los que el capital contribuye y de los que el capital se alimenta vorazmente, derivan, en resumen, de las actividades de diversos agentes e instituciones. Para el capital, esas 
innovaciones crean un vasto dominio de posibilidades siempre cambiantes para mantener o aumentar la rentabilidad. (Harvey, 2014, p. 103)

Se trata de una transformación de la industria cultural que trajo consigo crisis de empresas y mercado, debido al vertiginoso cambio tecnológico que varió las formas de producción y de consumo de la música. Las empresas productoras de fonogramas fueron arrastradas a una crisis de ventas que las obligó a modificar su base industrial tecnológica en aras de la supervivencia. El propósito de estas mutaciones tecnológicas responde al carácter evolutivo del capital económico. Harvey (2014, p. 107) recoge de Arthur la explicación de este fenómeno: la aparición constante de nuevas tecnologías provoca una cadena de adaptaciones, pero a su vez crean diversos problemas, es una economía en perpetua apertura al cambio tecnológico, produce nuevos nichos de rentabilidad pero al mismo tiempo genera destrucción de industrias.

La innovación tecnológica, a la que pequeños sectores informales han tenido acceso en los últimos años para grabar y reproducir cds y dvds, es un fenómeno que apareció al mismo tiempo que los procesos de marginación y exclusión como consecuencia de la aplicación del neoliberalismo en América Latina.

Este tipo de consumo, el cultural, que no es únicamente consumo de medios, puede ser definido como la utilización y/o apropiación que hacen los públicos o algunos de sus miembros - desde sus particulares referentes socioculturales- de los bienes o servicios portadores de significaciones así como de los equipamientos culturales disponibles en su entorno, estableciendo con ellos vínculos que posibilitan la producción de nuevos sentidos y dan lugar a variadas interacciones. (Torrico y Baldivia, 2005, p. 75)

La industria cultural que se ocupa de la producción musical se relaciona con varios sectores mercantiles empresariales para lograr la comercialización y consumo de sus productos: importadores, exportadores, distribuidores, comerciantes, medios masivos, agencias de publicidad, productores de espectáculos. Entre las mercancías que se comercializan se hallan los cds, dvds y hasta fines del siglo XX cassettes de música y discos de acetato. A estos sectores también se los denomina "agentes productores del sector empresarial fonográfico" (Torrico, 1999, p. 43).

La rentabilidad económica y el consumo condicionan a los distintos agentes y sectores de la industria cultural. Los medios masivos de comunicación trabajan con los principios y determinaciones del marketing, están estrechamente relacionados con la industria cultural que producen mercancías y refuerzan la ideología del consumo, son instancias de la industria cultural relacionados con la difusión de mercancías musicales de consumo masivo con contenido simbólico, se piensa como un proceso que incide en la conformación cultural de las audiencias o destinatarios, mediante la producción en serie y de modo mecanizado de canciones, en función del supuesto requerimiento del mercado. Torrico $(1999$, p. 3) situó su investigación sobre industria cultural a partir de las relaciones entre producción y el sistema de mercado.

Los sistemas de producción y comercialización de imágenes, entre los que se cuenta la producción audiovisual de artistas y canciones, presentan algunos rasgos especiales. La imagen es importante en la competencia del mercado de estas mercancías musicales, porque implica además del reconocimiento de marcas, la producción de sentidos que se asocian con "respetabilidad", "prestigio", "confiabilidad" e “innovación" “... La imagen sirve para instaurar una identidad en el mercado" (Harvey, 1998, pp. 318, 319). 
En otro estudio Podestá (2007, p. 111) expone, a manera de ejemplo relevante, cómo un producto musical marketeado por la industria cultural alcanza éxito, en plena época de globalización y neoliberalismo, es el caso del bolero que el mexicano Luis Miguel con su disco Romances vendió hasta alcanzar la cifra de 9 millones de ejemplares. La promoción de discos como éste, de acuerdo con Bourdieu (1997, p. 58; 2000, p. 12 ), obedece a un campo de competencia por el mercado y el capital simbólico de los artistas que alcanzan popularidad sobre la base de un valor puramente mercantil (Moncada, 2013, pp. 87, 88).

La música es uno de los bienes producida como mercancía por la industria cultural, sumida en la tendencia de concentración y acumulación del capital, en busca de la máxima rentabilidad, de modo masivo, característica de la economía moderna.

Un videoclip musical que difunde un canal de televisión o una canción que un programa de radio lo pone al aire, es una producción simbólica, condicionados o sometidos por factores comerciales, y de competencia, para lograr índices de audiencia. (Bourdieu, 1997, p. 68). Por tanto, es la lógica del mercado, el "marketing", lo que determina la difusión que un medio masivo hace de las producciones simbólicas o culturales. (Moncada, 2013, p. 84)

Rincón $(2008$, p. 161, 162) pone en duda las condiciones de la creación musical, sugiere debatir si son los artistas y compositores los que determinan una obra por su formación estética o son condicionados por propósitos empresariales y/o por el mercado, debido a la rentabilidad que supone la producción de canciones para el consumo.

La industria cultural musical en relación con los medios masivos su ubican en un campo definido por lo que está en juego y por los intereses específicos de los agentes y las instituciones que participan en este campo. Esta producción mercantil musical -cuyos vehículos son los medios masivos de comunicación y las distintas plataformas de internet como redes sociales y páginas web- convirtió los productos artísticos (cine, música, literatura, pintura, etc.) en bienes de consumo al alcance de un gran porcentaje de audiencia.

Para que estos productos simbólicos lleguen a sus destinatarios las industrias culturales, relacionadas con los medios masivos y el mercado, seleccionan a los artistas y sus propuestas musicales. Bourdieu (2002, p. 49) plantea que la vida política y la vida intelectual están cada vez más sometidas a la presión de los medios. (Moncada, 2013, p. 84)

Las audiencias y consumidores de música se sitúan dentro de un mercado relacionado con la socialidad y la expresión de sentimientos dentro de patrones culturales y de un contexto social. Esta referencia simbólica de la música se explica porque es un lenguaje que comunica sentimientos y vivencias que no puede expresar el lenguaje verbal. La música habla con sonidos y socializa un mundo infinito de sentidos, cada tema musical puede tener distinto significado para dos o más individuos (Hormigos, 2010, p. 92).

Hay estudios que evidencian nuevas formas de distribución independientes de la industria cultural musical. Las nuevas tecnologías vinculadas con el internet y aparatos como "teléfonos inteligentes" y "tablets" han creado una multiplicidad de canales de acceso a una cantidad importante y dispersa de producciones musicales autónomas e independientes de las empresas de producción musical. Existe una sobreabundancia 
de música que convierten a los individuos en omnívoros, según Hormigos (2010, p. 96): escuchan un poco de todo pero no llegan a apreciar la función comunicacional de la música.

La difusión de las computadoras, de las bases de datos, de los sistemas de información y la multiplicación de programas con aplicaciones diversas modifican las relaciones sociales, los sistemas de enseñanza, los sistemas científicos y los intercambios económicos. El nuevo espacio informacional y comunicacional (multiredes, multicanales) constituye un nuevo tejido cultural. (Pérez, 1995, p. 31)

Otras investigaciones analizan los cambios del sentido de industria cultural, debido a las mutaciones tecnológicas que han obligado a los consumidores musicales, por ejemplo, a variar con más frecuencia sus equipos desde donde escuchan canciones o melodías, y desde donde se advierten variaciones de roles de autor, actor y espectador por la experiencia con estas nuevas formas tecnológicas de productos culturales. La conversión del tocadiscos de acetato o de la grabadora de cassette o de dvd y su asimilación en un soporte como un computador fijo o personal, o de tecnologías con pantalla y formato de celulares, diversifica las opciones de un usuario que combina el escuchar música con otras actividades de ocio relacionadas con vídeos, juegos, chat en línea, etc. (Rodríguez, 2011, p. 152)

Según Fouce (2010, p. 71), el consumo musical basado en la gratuidad de las redes en internet, desde donde los usuarios acceden a la producción musical, afectó el modelo de negocio de la industria cultural fonográfica. Este autor sugiere que la tarea de los investigadores es preocuparse por la reconfiguración de las mediaciones que producen estas nuevas tecnologías dentro de los modos de organización de la cultura contemporánea.

Las tecnologías de la información en todas sus aplicaciones (telemática, informática, robótica, burótica) están transformando las relaciones sociales, los sistemas económicos y políticos. La sociedad de la información aparece como una de las dimensiones de la nueva civilización. (Pérez, 1995, p. 32)

\section{PRODUCCIÓN Y CONSUMO DE MERCANCÍAS MUSICALES, PODER SIMBÓLICO Y CULTURAS ANDINAS}

Otras corrientes de investigación reflexionan la industria de la música con procesos conflictivos de poder simbólico, dominación y hegemonía, ya que la creación musical solo se explica dentro de procesos de comunicación y de significación social e histórica:

El poder simbólico se ubica en uno de los campos (económico, político, científico, artístico) en que la vida social se representa. El campo se constituye por un capital común y por la lucha por su apropiación. Es un acumulado de conocimientos, habilidades, creencias, etc. Quienes dominan este capital detentan el poder o la autoridad del campo (García Canclini, 1990, pp. 13, 14).

La violencia simbólica en procesos mediáticos y de industria cultural es un tema de reciente preocupación de estudios en Latinoamérica. Becerra $(2005$, p. 95$)$ analiza la violencia simbólica sobre la base de los aportes de Bourdieu que la concibe como la adhesión de sujetos violentados a formas que se les impone como esquema de pensamiento de las que estos individuos no pueden escapar por voluntad propia. Es una violencia relacionada con el conocer y el querer. Para Becerra, este tipo de violencia también se encuentra en relatos que circulan mediáticamente. 
La primera propiedad de la violencia simbólica -violencia de la representación- como de cualquier hecho cultural es su relatividad, desde la que lo banal y lo efímero consagran lo que tiene de líquida y provisional nuestra época y sus habitantes. (Becerra. 2005, pp. 101, 102)

Los relatos contienen un "poder de representación", que estabiliza ciertos sentidos sociales sobre el mundo (Regillo, 2008). Este concepto de "poder de representación" se podría relacionar con el de poder simbólico cuando alude "...las tensiones y luchas que atraviesan a la comunicación masiva, así como al modo en que podría tributar tanto a la dominación como a su desafío" (Somohano, 2012, p. 6)

Los bienes simbólicos se ubican en tres modos de producción y mercados relacionados con el gusto de las clases sociales: burgués, medio y popular. Lo popular para García Canclini (1989, pp. 191 y ss.) está relacionado con lo tradicional y lo subalterno, se opone a lo culto, a lo moderno y a lo hegemónico, implica dominación de los sectores que detentan el poder y lo moderno, y que subordinan lo popular.

Se concibe al poder como la capacidad de un agente para actuar en función de la consecución de sus intereses y de intervenir o afectar los resultados de terminados acontecimientos, ceñido al manejo y acumulación de recursos. El poder simbólico es el que determina la producción y socialización de formas simbólicas significativas (Thompson, 199, pp. 29, 33). Requiere de un conjunto de condiciones técnicas, conocimientos sobre los procedimientos y una estructura en el marco de un sistema sociocultural. (Moncada, 2013, p. 84)

García Canclini (1989, p. 223), asegura la existencia de vínculos entre lo tradicional y lo moderno, lo popular y lo culto, lo local y lo extranjero. Fenómenos que se constata en países andinos, desde los noventa del siglo pasado hasta comienzos del siglo XXI han subsistido en Ecuador y Bolivia expresiones auspiciadas por el poder y las élites que han convivido con las manifestaciones musicales de culturas populares; en el caso ecuatoriano conviven diversas expresividades tradicionales y modernas, se encuentran lo indígena con lo vanguardista, lo "erudito" con lo popular... (Mullo, 2009, p. 28).

En Ecuador, Mullo (2009, p. 77) sugiere discutir el nexo entre la música recolera ${ }^{1}$ y la tecnocumbia ${ }^{2}$, tendencias musicales de carácter masivo y popular cuyos contenidos se relacionan con la modernización, la urbanización, la migración, el desarraigo, la marginación.

En el campo social de la rocola y la tecnocumbia, géneros de la industria cultural de música popular, se inscriben violencia simbólica y disputa de intereses por parte de medios masivos y anunciantes publicitarios, en torno a los artistas que se constituyen en capital simbólico. La violencia simbólica y la dominación también se expresan en relatos de canciones rocoleras y de tecnocumbia, que circulan en intercambios

1 Rocolera se la denomina a la música popular que se difundía mediante un aparato electromecánico que ponía discos de acetato, se ubicaba en bares y cantinas. La música rocolera tiene como referente la música del guayaquileño Julio Jaramillo (Mullo, 2009, p. 75).

2 La tecnocumbia se consolida en la década de los años 1990, se manifiesta en grandes concentraciones populares de festivales y shows artísticos, se trata de una interculturalidad musical que mezcla el ritmo de la cumbia colombiana con ritmos ecuatorianos como el sanjuanito, el danzante o el yumbo, su orquestación se logra mediante procedimientos técnicos con un sintetizador en un estudio de grabación (Mullo, 2009, p. 77). 
comunicacionales a partir de cds, dvs, internet y medios masivos, por ejemplo con temáticas de canciones sobre la migración y la marginación (Moncada, 2013, pp. 82, 86).

Un ejemplo de violencia simbólica es lo que un medio de comunicación publicó sobre Delfín Quishpe, al que reconoce éxito pero lo denigra. Quishpe adquirió fama a partir de la publicación de una de sus canciones en Youtube, su fama se inició con las redes sociales.

La revista digital Rolling Stone (2012) edición española, en una entrevista realizada a Delfín Quishpe, lo presenta con un sentido paradójico: "hace el ridículo como 'tonto listo' o todo lo contrario"; información que connota desprecio o degradación hacia un artista de origen social pobre e indígena. Este medio resalta lo grotesco de la canción popular, expresa violencia simbólica por el sentido peyorativo y ofensivo del tratamiento informativo. Rolling Stone destaca que Quishpe ha logrado superar la miseria y saltar a la fama gracias a YouTube. Con esto coincide el periódico digital BBC Mundo (2010), al publicar: "Delfín Quishpe es un fenómeno musical en internet". (Moncada, 2013, pp. 88)

\section{MASIFICACIÓN VERSUS DIVERSIDAD CULTURAL EN OTAVALO Y EN EL ALTO}

El problema de la masificación ha sido materia de preocupación de estudios sobre la industria cultural porque la cultura de masas, creada por la racionalidad tecnológica desde el paradigma de la modernidad capitalista es hegemónica. Pero en países latinoamericanos esta masificación subsiste frente a otras culturas populares que viven, se amalgaman e influyen mutuamente dentro de un amplio abanico de diversidad cultural.

La industria cultural genera masificación frente a una extraordinaria diversidad cultural que existe en países latinoamericanos. Hay una producción de música en países como Ecuador y Bolivia relacionada con procesos tradicionales, rituales, de identidades y de memoria histórica, de carácter local, regional y marginal y otra producción ligada a incipientes industrias culturales. Asimismo, la cultura popular está inserta en procesos hegemónicos de producción cultural y experiencias excluyentes producto de relaciones conflictivas (Mullo, 2009, p. 15).

La producción de mercancías musicales en Otavalo y en El Alto es de pequeña escala, dentro de lo que Narváez (2008, p. 32) caracteriza como producción mercantil simple, en la que los productores directos son propietarios de los medios de producción y controlan o intervienen directamente en el resto de procesos de distribución y comercialización de los productos.

Los productores y comerciantes de mercancías musicales de Otavalo han desarrollado estrategias orientadas a la especialización de artesanías y textiles, fundados en conocimientos ancestrales (Flores, 2009, p. 45). Las relaciones sociales, identidades, producción simbólica y de sentidos ligadas a la economía comunitaria de los indígenas otavaleños se ha reproducido durante décadas.

Dista mucho de la gran industria cultural en la que el trabajador fabricante directo no es propietario de los medios de producción, lo es el capitalista, y el saber ha sido subsumido a la tecnología, lo que origina una independencia del trabajo respecto de las condiciones objetivas de los medios de producción, concebido 
como alienación. Además la plusvalía que controla y se apropia el capitalista es fundamental en el valor de cambio de la mercancía, prima, por tanto, más el valor de cambio que el valor de uso, características de la gran industria cultural organizada como empresa capitalista (Narváez, 2008, pp. 37, 38).

En relación con Otavalo, el valor de uso simbólico se relaciona directamente con procesos de creación cultural originales de agrupaciones musicales de comunidades indígenas pero que no descuidan su relación con procesos de la modernidad capitalista. En la actualidad, el grupo Samy es de los más escuchados en Otavalo, tiene tres grabaciones, el último se lanzó en junio del 2013. Los discos sirven para promocionar al grupo y los venden en sus presentaciones. La piratería quita al grupo su producción y su trabajo. El grupo no vive de la venta de cds, éstos procuran la imagen del grupo. Tampoco estos artistas tienen relación con empresa o industria cultural. En las radios de la provincia: Radio Satélite Otavalo y Radio Ilumán son las que promueven la música del grupo. En el canal UTV de la universidad Técnica del Norte, es un canal provincial también se ha promocionado al grupo. Además el grupo participó en la Caja de Pandora, programa de Ecuador TV, con señal nacional (Pineda, entrevista, 2013).

Estas agrupaciones de música de Otavalo generan sus propias condiciones para grabar y promocionar su trabajo musical ya sea como agrupación o con su participación en rituales o fiestas importantes para su comunidad. Los Charijaya, los Llarina que son grupos posteriores a Ñanda Mañachi, tiene cada uno su propia productora, pequeño estudio de grabación, porque son jóvenes con iniciativa. Esto debido a la tradición otavaleña estos grupos producen y comercializan al mismo tiempo. Es una producción que los grupos venden en sus conciertos y presentaciones. Y los propios ensambles que salen mucho al exterior lo venden en sus viajes, en lugares pequeños y marginales. Alguien invierte individualmente pero hay una relación familiar con padres e hijos, el núcleo familiar es el que produce, casi siempre los grupos de música lo integran los miembros de una familia ampliada, con excepción hay músicos fuera de la familia. (Kowii, entrevista, 2013)

El acceso a la tecnología ha generado una tremenda caída de la producción discográfica empresarial, hay una producción independiente de estudios de grabación digitales que funcionan con una computadora, al alcance de grupos musicales que empiezan o que quieren difundirse para hacer una grabación en una habitación sin condiciones acústicas mínimas, donde no se filtran sonidos externos como ladrido de perros, porque no tienen una tecnología para filtrar estos sonidos ajenos al cd, y logran vender con una pequeña producción para promocionarse (Junaro, entrevista, 2013).

Desde la década de 1980 en la ciudad de El Alto se consolidan varias entradas o procesiones con fraternidades en las que danzantes y bandas de músicos de instrumentos de bronce (bajos, contrabajos, tubas, clarinete, "pífanos" metálicos, bombo, platillo) interpretan melodías con frecuencia compuesta para cada año en ritmos de morenada, kullawada, caporales, tarqueada, mohoceñada, entre otros. Las bandas graban en pequeñas y medianos estudios de grabación, un tiraje de mil cds para entregar a pasantes de fraternidades, invitaciones, programas de radio con creaciones, son producciones que se logran con el financiamiento de los integrantes de cada banda. Los cds la mayoría las regalan o las venden en sus presentaciones, no tienen conexión con industrias culturales o las industrias artesanales o con los quioscos 
de cds. Los quioscos o negocios pequeños piratean sin dar ninguna contribución a los artistas, venden a un promedio de 5 pesos bolivianos cada cd, equivalente a 0,70 centavos de dólar (Mamani Laruta, entrevista, 2013).

Los negocios de cds y dvds venden diversos temas relacionadas con fiestas, rituales, romances o decepciones amorosas y con la vida cotidiana. Es interesante la interpretación que uno de nuestros informantes diera a la preferencia de melodías y canciones con ritmos nuevos como la música chicha que gusta y suena por parte de transportistas, porque su ritmo lo relaciona con los motores para que los mantenga despiertos (Mamani Colque, entrevista, 2013).

En Bolivia hay una discusión sobre si se puede hablar en este país de industria cultural. La industria discográfica está tan venida a menos o en crisis que no podemos discutir sobre la existencia de industria cultural. Hay una crítica acérrima y bastante miope sobre la denominada piratería que se supone que está originando la quiebra de las empresas discográficas bolivianas. Hay simultaneidad y paralelismo, hay industria cultural con reproducción de discos que coexisten con pequeños negocios que reproducen cds y dvds ilegales y piratas que pudiera ser más poderosa que la gran empresa, pero no hay relación directa o conexión entre la gran industria y los negocios piratas. Los medios masivos utilizan los productos de ambas ofertas. Es una ensalada que los medios usan, ambos bienes que están circulando. Los músicos no ganan por la venta de discos. Los cds sirven para promocionarse, sus ingresos los obtienen de los conciertos y presentaciones en contratos (Rozo, entrevista 2013).

El ensamble musical Savia Nueva, por ejemplo, no vive de la música, la dinámica ha cambiado, aunque es una banda de once personas y el proceso de producción es muy complejo, por eso el grupo no circula como antes. El medio boliviano no resiste un grupo de esta naturaleza, es un mercado que absorbe música de otros géneros más simples. Savia Nueva logra producir un concierto grande, que repite cada cierto tiempo, con una empresa que organiza Villa del Mar. Savia Nueva es más un patrimonio cultural antes que de rentabilidad, su música se ha difundido mucho, por eso se piensa en conciertos de calidad de vez en cuando, no es factible para conciertos en lugares pequeños, requiere de cinco mil personas para pagar al grupo (Junaro, entrevista, 2013).

Los vendedores de productos musicales en negocios de El Alto están sindicalizados, son reconocidos como parte de gremios que aglutinan a distintos ámbitos de comercio (electrodomésticos, ropa, muebles, etc.), cada quiosco paga en función de las normas del sindicato de comerciantes minoristas. Estos negocios de venta de cds o de instrumentos musicales no tienen relación con la gran industria. Venden en función de lo que las radios y televisiones difunden; Radio Chacaltaya que difunde música chicha, o cumbia rápida y programas de radio y televisión como el programa Folk u otros de género tropical, esta música se promociona también en canal 24 a las $22 \mathrm{~h} 00$, o en el canal 23 , también en el horario de las $2 \mathrm{~h} 00$ que difunde música chicha. (Mamani Colque, entrevista, 2013) 
Hay composiciones musicales que contrata el pasante ${ }^{1}$ para que durante todo el año se los difunda por radio, televisión, en las preentradas y las Entradas ${ }^{2}$. Hay temas religiosos, otros que dependen de las preferencias del pasante y de la negociación de los músicos, temas modernos desde el amor, la traición, como los huayños ${ }^{3}$ andinos (Tassi, entrevista, 2013).

Las radios comunitarias de mediano alcance responden a una organización barrial de El Alto, se encuentra rap, música chicha, tecno, tropical andina, ligadas a organizaciones de fiestas y centros culturales de migrantes del campo que bajo parámetros comunitarios se organizan en el contexto urbano. Hay una cobertura y relación de radios comunitarias con grupos de música. La cantidad de huayño peruano tropical es inmensa con respecto a lo que producen los grupos de música de El Alto, que no tienen forma de competir, incluso forman grupos para copiar la música peruana. Existe una importante difusión en radios comunitarias de lo que producen otros países como Argentina, Colombia y México, que también se difunde en estas radios comunitarias rancheras, cumbia mexicana, son, etc. (Rozo, entrevista 2013)

Existe una producción audiovisual maravillosa, fortísima de danzas de cholitas con pollera corta que trabajan huayño y ritmos tropicalizados del Perú. En DVD y $\mathrm{mp} 4$ de formato chico de vídeo, y de formato para celulares. En El Alto se venden compilaciones de estos vídeos producidos en Cochabamba desde donde también hay una construcción estética. En Youtube se difunden estos vídeos que se comercializan en El Alto. La música popular en El Alto demuestra el proceso de cambio y sincretismo permanente que sus artistas y músicos populares impulsan. Sin perder su función ritual, la música popular se adapta a nuevos ritmos y a la industria cultural y artesanal que produce $c d s$, dvds, instrumentos de música que consumen los pobladores y turistas en esta ciudad. En El Alto hay un formato familiar de los negocios e integrantes, directores de grupos. No hay la forma de socios. Hay parentesco o vínculo comunitario entre los grupos de danza y música con los rituales. Los negocios y radios comunitarias funcionan con los mismos parámetros de las fraternidades (grupos de danza y música de distintos ritmos que desfilan por sectores urbanos en las Entradas o procesiones) de las grandes fiestas, hay cientos de fiestas barriales y las mega fiestas como el Gran Poder de La Paz, Carnaval de Oruro, 16 de Julio en El Alto (Rozo, entrevista 2013).

\section{CONCLUSIONES}

En síntesis, en las ciudades indígenas andinas con predominio kichwa de Otavalo y con preeminencia aymara de El Alto, se conjuga una multiplicidad de mecanismos culturales mestizos andinos que sobreviven con la

1 El pasante es elegido por una fraternidad, es el encargado de financiar distintos eventos hasta llegar a las Entradas, también llamado preste en Bolivia. En Ecuador al pasante se lo conoce con el nombre de prioste.

2 Las Entradas son procesiones o desfiles religiosos de distintos ritmos musicales en las que participan grupos de danzantes y músicos.

3 El huayño es un ritmo musical binario, andino prehispánico, es alegre, marcado por el bombo como percusión fundamental (Arnaud y Mayta, 2010). Los ensambles tradicionales de interpretación de este ritmo lo integran, además del bombo, el charango, la guitarra e instrumentos de viento, especialmente quena y zampoñas. 
lógica mercantil del capitalismo para socializar y comercializar mercancías musicales de artistas, rituales y celebraciones; en una relación compleja entre redes informales de comercio, medios comunitarios, el aparato mediático audiovisual de cobertura regional y nacional, el internet que operan en Ecuador y en Bolivia. Es un amplio campo de estudio que todavía debe prosperar.

\section{BIBLIOGRAFÍA}

Arnaud, G. y Mayta, E. (2010). "Membrillos para espantar el k'ita Carnaval. Pandillas de carnaval en Semana Samasa Alta. Diablos tentadores y pinkillus embriagadores ...en la fiesta de Anata/Phujllay. Estudios de antropología musical del carnaval en los Andes de Bolivia. Tomo 1, Universidad Autónoma Tomás Frías, La Paz: Plural Editores.

BBC Mundo (2010). Delfín Quishpe, un fenómeno musical en Internet (www.bbc.co.uk/mundo/noticias/2010/12/101201) (visitada en abril 19, 2013).

Becerra, Jesús (2005). “Culturas de Pantalla y Violencia Simbólica”. Quórum Académico. Vol. 2, Nro. 2: 89-103. www.redalyc.org (visitada en febrero 18, 2013)

Bourdieu, Pierre (1997). Sobre la televisión. Barcelona: Editorial Anagrama.

Bourdieu, Pierre (2002). Pensamiento y acción. Buenos Aires. Libros del Zorzal.

Cavour, Ernesto (2010). Instrumentos musicales de Bolivia. 3era. ed., La Paz: Producciones Cima editores.

De Munter, Koen (2010). "Tejiendo reciprocidades: John Murra y el contextualizar entre los aymara contemporáneos". Revista Chungara, Vol. 42, No. 1: 247-255. www.chungara.cl/ (visitada en marzo 15, 2014)

Ecured (2014). “El Alto (Bolivia”. Disponible en www.ecured.cu (visitada en junio 22, 2014).

Escobar, Arturo (2010). "América Latina en una encrucijada: ¿modernizaciones alternativas, posliberalismo o posdesarrollo?". Saturno devora a sus hijos: Miradas críticas sobre el desarrollo y sus promesas. Barcelona: Editorial Icaria.

Flores, Lena (2009). "Las políticas públicas para el desarrollo económico local de Otavalo". Disertación de Maestra en Ciencias Sociales, mención Desarrollo Local y Territorio, FLACSO-Ecuador.

Fouce, Héctor (2010). "Tecnologías y medios de comunicación en la música digital. De la crisis del mercado discográfico a las nuevas prácticas de escucha". Revista Comunicar, No. 34: 65-72. www.revistacomunicar.com/ (Visitada en febrero 10, 2013)

García Canclini, Néstor (1989). Culturas híbridas. Estrategias para entrar y salir de la modernidad. México: Editorial Grijalbo.

García Canclini, Néstor (1990). Introducción. La sociología de la cultura de Pierre Bourdieu”. México: Editorial Grijalbo.

Gacía Canclini, Néstor (2000). "Industrias culturales y globalización: procesos de desarrollo e integración en América Latina". Revista Estudios Internacionales, Vol. 33, No. 129, www.avancesveterinaria.uchile.cl (visitada en mayo 12, 2013) 
Gérard, Arnaud (2010). "Tara y tarka Un sonido, un instrumento y dos causas (Estudio organológico y acústico de la tarka)". Diablos tentadores y pinkillus embriagadores ...en la fiesta de Anata/Phujllay. Estudios de antropología musical del carnaval en los Andes de Bolivia. Tomo 1, Universidad Autónoma Tomás Frías. La Paz: Plural Editores.

Gobierno Autónomo Descentralizado de Otavalo (2013). Actualización del Plan de Desarrollo y Formulación del Plan de Ordenamiento Territorial del Cantón Otavalo. Disponible en www.Otavalo.gob.ec (visitada junio 19, 2014).

Gobierno Autónomo Municipal El Alto (2014). "Historia de la ciudad de El Alto". Disponible en www.elalto.gob.bo (visitada en junio 22, 2014).

Godoy, Mario (2005). Breve Historia de la Música del Ecuador. Quito: Corporación Editora Nacional.

Harvey, David (1998). "Compresión espacio-temporal y condición postmoderna". La condición de la posmodernidad. Buenos Aires: Amorrortu Editores.

Harvey, David (2003). “La globalización contemporánea”. Espacios de Esperanza. Madrid: Editorial Akal.

Harvey, David (2014). 17 Contradicciones y el fin del capitalismo. Quito: IAEN.

Hormigos, Jaime (2010). "Distribución musical en la sociedad de consumo: La creación de identidades culturales a través del sonido". Revista Comunicar, No. 34: 91-98. www.revistacomunicar.com/ (visitada en febrero 10, 2013)

Kowii, Ariruma (2005). "Cultura kichwa, interculturalidad y gobernabilidad". Revista Aportes Andinos, No. 13. www.uasb.edu.ec/padh (visitada en julio 20, 2014).

Lalander, Rickard (2009). "Dilema intercultural y lucha indígena en Otavalo, Ecuador". Bicentenario, Anales N.E. No. 12.

Moncada, Raúl (2013). "Violencia simbólica en la música rocolera y tecnocumbia”. Revista Chasqui, No. 123: 8290. www.revistachasqui.com/ (visitada en noviembre 14, 2013)

Mullo, Juan (2009). Música Patrimonial del Ecuador. Quito: Fondo Editorial del Ministerio de Cultura.

Narváez, Ancízar (2008). "El concepto de industria cultural". Industrias culturales, músicas e identidades. Bogotá: Pontificia Universidad Javeriana.

Ordóñez, David (2011). "Ritual del Mimula”. XXV Encuentro Anual de Etnología-RAE 2011. La Paz: Museo Nacional de Etnografía y Folklore.

Ortiz, Santiago (2012). ¿Comuneros Kikchwas o ciudadanos ecuatorianos? La ciudadanía étnica y los derechos políticos de los indígenas de Otavalo y Cotacachi (1990-2009). Quito: FLACSO-Ecuador.

Parra, León (2009). “Un análisis de la dinámica productiva del sector informal en las ciudades de la Paz y El Alto, Bolivia en 2009: el caso del sector textil". Revista Ean, No. 70: 150-156. www.journal.ean.edu.co/index.php/Revista/article/view/542/529 (Visitada en noviembre 14, 2012)

Perez Lindo, Augusto (1995). Mutaciones, Escenarios y Filosofías del Cambio del Mundo. Buenos Aires: Editorial Biblos.

Podestá, Juan (2007). "Apuntes sobre el bolero: desde la esclavitud africana hasta la globalización”. Revista Ciencias Sociales, No. 19: 95-117. www.revistacienciasociales.cl/ (visitada en febrero 15, 2013) 
Ramonet, Ignacio (2002). "El tratamiento de la información económica en el periodismo de hoy", ponencia presentada por el aniversario del Fondo de Garantías de Depósitos y Protección Bancaria, FOGADE, abril 4, Caracas. Disponible en www.analitica.com (visitada en julio 17, 2012.)

Ramonet, Ignacio (2010). "Una reflexión sobre los medios y la democracia", Resumen conferencia Ignacio Ramonet: CIESPAL. Disponible en www.lalineadefuego.info, visitada en julio 17, 2012.

Reguillo, Rossana (2008). "Saber y poder de representación: la(s) disputa(s) por el espacio interpretativo". Revista Comunicación y Sociedad, No. 9: 11-33. www.comunicacionysociedad.cucsh.udg.mx/ (visitada en febrero 15, 2013)

Rincón, Omar (2008). "Lo bailao no se quita. La música como práctica comunicativa y cultural”. Industrias culturales, músicas e identidades. Bogotá: Pontificia Universidad Javeriana.

Rodríguez, Marcelo (2008). Guía Metodológica en Multimedia de Instrumentos Andinos, utilización de Pífanos y Payas en la Educación Regular Musical y en el Quehacer Artístico de Niños, Jóvenes de Quito Sur y Barrios Aledaños. Quito: Ministerio de Cultura.

Rodríguez, Raúl (2011). “De industrias culturales a industrias del ocio y creativas: los límites del 'campo' cultural”. Revista Comunicar, No. 36: 149-156. www.revistacomunicar.com/ (visitada en febrero 10, 2013).

Rolling Stone (2012). Delfín hasta el fin: 'He madurado. No voy a cantar más sobre tragedias'.www.rollingstone.es/specials/view/delfin-hasta-el-fin-he-madurado-no-voy-a-cantar-mas-sobretragedias. (visitada en abril 19, 2013).

Somohano Fernández, Abel (2012). El concepto de poder simbólico como recurso para comprender la dimensión política de la comunicación masiva: hacia una posible articulación entre las propuestas de Pierre Bourdieu y John B. Thompson. Mediaciones Sociales, No.10: 3-33. www.ucm.es/info/mediars (visitada en abril 4, 2013)

Tassi, Nico (2010). Cuando el baile mueve montañas. Religión y economía cholo-mestizas en La Paz, Bolivia. La Paz: Fundación Praia.

Thompson, John, B. (1998): Los media y la Modernidad. Barcelona: Editorial Paidós.

Torrico, Erick (1999). Industrias culturales en la ciudad de la Paz. PIEB, La Paz.

Torrico, Erick y Baldivia, Alejandra (2005). "De las industrias a las actividades culturales: Los conceptos, las normas y la incidencia de los sectores culturales en la economía boliviana”. Dinámica económica de la cultura en Bolivia. Bogotá: Viceministerio de Cultura de Bolivia, Convenio Andrés Bello. 


\section{Entrevistas a informantes clave}

- Cachiguango, Alfonso, Compositor, Director y Músico del grupo de música tradicional "Ñanda Mañachi", Constructor de instrumentos andinos, Peguche, Otavalo, 10 de noviembre de 2012.

- Kowii, Ariruma, Poeta, Doctor en Estudios Culturales Latinoamericanos, Quito, 15 de noviembre de 2013.

- Junaro, César, Director del grupo Savia Nueva, Compositor, Antropólogo, La Paz, 20 de agosto de 2013.

- Mamani Colque, Clemente, Antropólogo, músico, Quito, 30 de octubre de 2012 y El Alto, 22 de agosto de 2013.

- Mamani Laruta, Clemente, Radiodifusor de programas relacionados con las bandas de instrumentos de bronce de la ciudad de El Alto, que participan en las Entradas de baile folklóricas, Bolivia, 27 de agosto de 2013.

- Pineda, Rodrigo, Músico integrante del Grupo Samy, Constructor de instrumentos andinos, Quinchuquí, Otavalo, 26 de diciembre de 2013.

- Rozo, Bernardo, Antropólogo, Etnomusicólogo, La Paz, 16 de agosto de 2013.

- Tassi, Nico, Investigador adjunto del University College London en temas relacionados con los pueblos indígenas de las tierras altas bolivianas, La Paz, 20 de agosto de 2013.

\section{Otra fuente}

Rodríguez, Wilmer y Tierra Libre (2012), El Mundo Sonoro de los Andes, cd de música, primer premio Concurso Discográfico, categoría étnica, Convenio Binacional Venezolano-ecuatoriano. Quito: Ministerio de Cultura del Ecuador. 